\section{ECONOMICS}

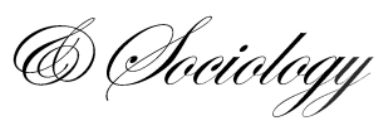

Caridad, L., Núñez-Tabales, J., Seda, P., \& Arencibia, O. (2020). Do Moody's and S\&P firm's ratings differ?. Economics and Sociology, 13(4), 173-186. doi:10.14254/2071-789X.2020/13-4/11

\title{
DO MOODY'S AND S\&P FIRM'S RATINGS DIFFER?
}

\author{
Lorena Caridad \\ University of Córdoba, \\ Córdoba, Spain \\ E-mail:d92calol@uco.es \\ ORCID 0000-0002-3406-9917 \\ Julia Núñez-Tabales \\ University of Córdoba, \\ Córdoba, Spain \\ E-mail:es2nutaj@uco.es \\ ORCID 0000-0001-6597-6029

\section{Petr Seda \\ VSB Technical University of \\ Ostrava, Crech Republic \\ E-mail:petr.seda@vsb.cz. \\ ORCID 0000-0002-2205-6377 \\ Orlando Arencibia \\ VSB Technical University of \\ Ostrava, Crech Republic \\ E-mail:orlando.arencibia@vvb.cz \\ ORCID 0000-0001-8217-2399}

Received: December, 2019

1st Revision: September, 2020

Accepted: December, 2020

DOI: $10.14254 / 2071-$

789X.2020/13-4/11

JEL Classification: G24, G17, F65, D53

\begin{abstract}
Credit rating agencies produce public statements about the financial health of companies, institutions, geographical entities and financial assets. The main available information about firms, useful for analyzing their long-term creditworthiness is their public accounts about the activities and results, besides the audit reports and their credit ratings. The agencies' results are mainly based on these data, but they claim to use additional qualitative information, with a methodology only partially disclosed. When different agencies produce long-term ratings about a particular firm, it should be expected that they were coincident, or at least similar, so that investors could use any of them to assess the potential financial risk. This is not the case, as the same companies can be rated differently by different agencies. This is the case with Standard and Poor's and Moody's: although their rating methods are not coincident, but their aim is to measure a similar latent variable - the firm's credit risk. These divergences could be caused, at least in part, by possible conflicts of interest or by a phenomenon called 'rating inflation'. A difference index is proposed to measure the differences in ratings when comparing several agencies' evaluations. The situation with the two main agencies is examined, using two large samples in a fiveyear period: clear discrepancies are observed, in some economic sectors, and similarities in others, with some evidence about getting higher ratings depending on a chosen agency. Also, a convergence of ratings during the period of 2014-2018 is observed, more prominent in some sectors, suggesting that additional regulation is needed to increase the market transparency.
\end{abstract}

Keywords: long-term ratings, conflict of interest, rating inflation, credit rating agencies, ratings evolution.

\section{Introduction}

Inflation of grades is a state of affairs which arouses a good share of comments in different environments. In the universities and schools systems of developed countries, there are many complaints about how students get high rates without having superior levels of 
achievements. Could it be a trend that produces spillovers in the rating of firms and institutions? Could the causal factors be similar? The use of sample data for companies rated by different agencies is employed to analyze these questions.

Companies ratings are used as a guide for investors and institutions to evaluate the credit risks associated with firms or financial assets. The assessment of the quality of default predictions in the financial sector has been analyzed by several authors (Engelmann et al., 2003, Becker and Milbourn, 2009) and it is of importance for market supervision. Beatty et al. (2018) studied the problem associated with the benefits of agencies and their influence in the ratings awarded; they look at the so-called recalibration of Moody's and Fitch, that allowed higher ratings with no apparent cause. This situation has been studied by Becker and Milbourn (2011) finding that the entrance of Fitch into this market is the original cause of rating inflation. Bonsall (2014) treats the impact of the issuer-pay model on bond rating as a fundamental factor, and the changes (increases) in fees compared to the original investor-pay model. Ratings' base function is to measure the financial health of a company, in an objective and unbiased way, to bridge the information gap between the management of a firm and its investors (Sabatino, 2014), shareholders, customers, and, why not, employees. Also, they ought to provide a homogenous means of comparison between alternative investments, and finally, it means to set a common standard that can be used to inform about credit risks. Rating of a company is reduced to a partially quantitative figure or level. Of course, one has to take into account that there is a price to pay for this reduction of dimension: all the variables defining the economic and financial situation of a company and its environment (in the market, country, and situation of internal and external characteristics) is reduced to just an ordinal uni-dimensional figure: the long-term rating obtained by an external evaluator or agency. To complicate the state of affairs, it is not uncommon to have, for many firms and institutions, several ratings provided by different credit rating agencies (CRA's). Theoretically, these ratings should be almost coincident, as they are evaluating the creditworthiness of the same companies, although ratings by S\&P, Moody's or Fitch are not interchangeable. In the real world, these coincidences are not always the case, and different ratings may be awarded by CRA's to the same firm. Altman and Rijken (2004) study rating stability between different agencies. Escrig et al. (2019) treat the sustainability of ratings in a changing environment. Belas et al. (2015) use raw data to estimate business risks directly, but for small and medium companies. Some statistical methods have been used to discriminate between different levels of ratings, such as in Yakimova and Kuz (2019), with multivariate statistical techniques.

In financial literature, there are controversies about possible conflicts of interest because a CRA evaluating a firm is also its customer. Originally the independence of these judgments was stronger, as investors used to pay to obtain the rates along with the additional information about their prospective investments. But this ideal model has evolved towards a system where issuers themselves finance the research about their ratings. There could be a clear interest in lifting the rating of the company who is paying for it, contradicting the original purpose of the CRA's existence: smoothing of problems originated by the presence of asymmetric information at the markets (White, 2018). There is no counterparty in the control over the quality of ratings, but the reputation of the agencies. Some authors (Mathis et al. (2009), for example) question whether this is enough to discipline the raters; they model the tradeoffs between the interest of the agencies about their reputation and the issuers' desire to pay for being rated, with a predominance of the reputational concerns if the income associated is not decisive. Kartasheva and Yilmaz (2020) analyzed the precision of ratings and concluded that they are affected by errors, besides ratings inflation. 
Ratings are evaluated usually for financial assets, like bonds or credit operations; but also, to estimate the financial health of companies. And they are basic in assisting the investor's decisions, and in some cases, required by regulators or managers of funds. Long term prospects are the base of many investment procedures, and the CRA's provide these ordinal measures for different types of firms. Thus, when looking at firms anazed by different agencies, their assessments should be similar, as they use the same set of information (internal or external) to judge their financial health and future; here, long-term companies ratings estimated by S\&P and Moody's are compared, taking into account their financial variables, and focusing on the differences observed, that could be related to the possible inflation of rates, or the particular methodologies used by these agencies.

Ratings are derived from two types of sources: the first is based on financial data and public accounts on companies, that is on information that can be considered 'objective'; and the second is derived on what is referred as 'qualitative data', including news, reports and market comments, that belong to a flurry world of opinions and proprietary treatment of the agencies. In between, the methodologies used by different CRA's are only partially known.

CRA's final interest cannot be other than to achieve reliability in their evaluations. Reputation allows them to survive: they provide information, so their main asset is their trustworthiness transmitted by their reports to investors and other agents involved. This is achieved, on the long, run by the accuracy of their 'forecasts' about financial products or of companies, and, in general, this is the case, although only the big and scarce failures are the ones that are reported in the media.

Standard and Poor's and Moody's are the main global actors; their combined income is more than three-quarters of the agencies' market, followed by Fitch. The entrance of this firm into the rating market increased competition, but as Bae et al. (2015) show, this has only affected the market share of the larger agencies. S\&P charge their clients more than Fitch, as could be expected from a new actor trying to establish himself. It seems then this oligopoly could produce distortions, not only in the price charged to their customers, but also, and more worrisomely, in their judgments. But the very nature of the type of their activity produces a self-regulation that has survived and seems in good health today. Bonsall et al. (2018), consider that widely covered firms are more accurate, as they would affect the agencies reputation in case of financial non-forecasted problems. As Xia (2014) points, the investorpaid CRAs tend to improve the quality of ratings, while the issuer-paid agencies produce less informative results. Xia and Strobl show that the issuer-pays model originates inflated ratings for firms. Frenkel (2015) consider that CRAs aim at maintaining a reputation for credibility for markets and investors, while, at the same time, develop a different image for issuers that could be their future clients. Skreta and Veldkamp (2009) propose a model to simulate situations where rating inflation occurs, especially when the assets are sufficiently complex. Chodnicka-Jaworska (2017) conclude that there are no differences in bank's ratings for the main agencies, although, the largest CRAs tend to attribute higher ratings. Whalen, (2016), analyses the conflict of interest for the four largest auditors. Goldstein and Huang (2020) confirm this bias in the information provided to creditor, leading to inflated corporate ratings, and propose a model to investigate the information effects on firms' investments, taking into account the endogeneity of the rating's effects in determining investment decisions. Also, Patrick (2016), in his dissertation thesis, reaches the same conclusion, comparing the big three rating firms and the four largest audit firms, that share a common issuer-pay business model. Josephson and Shapiro (2020) analyze how competition affects credit ratings, and, in the case of Fitch, conclude that competition does not lead to rating inflation. Beatty et al. (2019) investigate how recalibration of municipal bond ratings influences the market share of Moody's and Fitch. 
Both companies, S\&P and Moody's, use an ordering of rates which is similar: AAA is the highest value for S\&P's (Aaa in Moody's case), followed by AA+ (Aa1), AA (Aa2), AA(Aa3), A+ (A1), A (A2), A- (A3), BBB+ (Baa1), BBB (Baa2) and BBB- (Baa3), for the 'investment grade' levels. Non investment grades start at $\mathrm{BB}+(\mathrm{Ba} 1), \mathrm{BB}(\mathrm{Ba} 2), \mathrm{BB}-(\mathrm{Ba} 3)$, $\mathrm{B}+(\mathrm{B} 1), \mathrm{B}(\mathrm{B} 2), \mathrm{B}-(\mathrm{B} 3), \mathrm{CCC}+(\mathrm{Caa} 1), \mathrm{CCC}(\mathrm{Caa} 2), \mathrm{CCC}-(\mathrm{Caa} 3)$ and $\mathrm{D}(-)$ include the remaining rates.

Financial regulators impose some conditions on new bond emissions, such as having been awarded a certain level of rating. Thus, a mere 'opinion' upon the financial situation of firms, becomes a regulatory condition. The failure of ratings in the 2008 financial crisis produced a new wave of regulatory activity upon the CRA's reports (and on audit firms), distorting the original purpose of providing information to investors willing to pay for this information. In the United States, the National Registered Statistical Rating Organization has been raising barriers for a firm to be considered as a recognized CRA. The Enron default, with some others, and later, the subprime mortgage crisis, prompted new regulation with the 2006 Credit Rating Agency Reform Act, aiming at the possibility of comparisons between registered agencies. In Europe, after Basel II, the financial regulators in each country witch CRA's ratings can be recognized in some instances, such as the determination of the capital of banks and bond issues. Control of the agencies by states or governments is not the norm. Their recognition is based on a set of minimum standards (Blaurock, 2007), and the market evolution since the seventies has not achieved a satisfactory status quo so that the agencies can achieve the desired levels of reliability and independence of their judgments. The regulations in Australia (2018) and the United States could be a first approach to the problem. The former assess the adherence to the methodology and review the assumptions made for rating; they use an analytical approach, rather than the classical compliance review. EU regulation requires that the methodology used by the agencies should be "continuous, systematic, rigorous and potentially subject to validation" (Hemraj, 2015).

Kramer and Güttler (2008) compare the ratings of a set of companies rated in 1998 by S\&P and Moody's recording the defaults up to 2002 and estimate a slightly higher probability of default for S\&P's rated companies. Nowadays it is surprising, and reassuring, that using different methodologies the results are so close.

To analyze these discrepancies a large sample of companies is taken over several years (in section 2), with their corresponding public account data; ratings from S\&P and Moody's are compared over several economics sectors, in section 3. Systematic departures were detected, and, these could be linked to inflation of ratings, associated to the conflict of interest deriving from the issuer-pays model. An index to measure the intensity of these differences is proposed in section 4, and how the differences vary in the following years. Finally, some conclusions about the inflation of ratings and the conflicts of interest are included in section 5, with some policy proposals.

\section{Data}

To analyze rating inflation two large samples from Bloomberg's database of $n=1094$ companies in 2014 and $n=1112$ in 2018 are analyzed; for 892 firms in 2014 and 778 in 2018, both ratings ( $S \& P$ and Moody's) are available, with the main figures for their public account data, and thus, they could be used for comparisons, although their differences could be partially attributed to the rating methodologies used by each CRA and with their particular adaptation to the economic sector where firms are classified. The selected companies belong to different economic sectors, as can be seen, in table 1 . 
Table 1. Structure of the sample.

\begin{tabular}{|c|c|c|c|c|}
\hline \multicolumn{3}{|c|}{ Sample size } & \multicolumn{2}{|c|}{ Sample size } \\
\hline Sector & $\begin{array}{ll}2014 & 2018 \\
\end{array}$ & Sector & & $\begin{array}{ll}42018 \\
\end{array}$ \\
\hline Consumer & $105 \quad 105$ & Mining & 52 & 52 \\
\hline Energy & 90 & Paper I. & 28 & 28 \\
\hline Healthcare & 73 & Chemical & 76 & 46 \\
\hline Hotel & 21 & Retailing & 71 & 71 \\
\hline Industrial & $244 \quad 256$ & Telecom & 47 & 48 \\
\hline Information $\mathrm{T}$. & $125 \quad 126$ & Utilities & 127 & 128 \\
\hline Media & 65 & Total & 1094 & 1112 \\
\hline
\end{tabular}

This distribution has been obtained without a priori constraints in the random selection of companies in the original database, formed by thousands of companies. The information is available using Bloomberg's terminals, where, besides the ratings, the public accounts of companies are also accessible. The sample size would allow precise estimates of proportions, with a sampling error less than $\pm 0.1 \%$ with a $99 \%$ confidence for each full sample. As some sector of companies are studied, the sampling error will be higher for subsets of the firms. Selecting a large sample is oriented to be able to study in details some of the formers sectors.

The distribution of the S\&P and Moody's long-term ratings for these firms is presented in table 2 .

Table 2. S\&P and Moody's rating distributions

\begin{tabular}{cccccccccc}
\hline & \multicolumn{2}{c}{ Frequency } & \multicolumn{2}{c}{$\%$} & Moody's & \multicolumn{2}{c}{ Frequency } & \multicolumn{2}{c}{$\%$} \\
S\&P & 2014 & 2018 & 2014 & 2018 & & 2014 & 2018 & 2014 & 2018 \\
\hline AAA & 3 & 3 & 0.3 & 0.3 & Aaa & 3 & 3 & 0.4 & 0.4 \\
\hline AA+ & 2 & 2 & 0.2 & 0.2 & Aa1 & 3 & 1 & 0.3 & 0.1 \\
\hline AA & 11 & 7 & 1.0 & 0.7 & Aa2 & 5 & 5 & 0.6 & 0.6 \\
\hline AA- & 24 & 21 & 2.2 & 2.2 & Aa3 & 10 & 10 & 1.1 & 1.2 \\
\hline A+ & 39 & 37 & 3.6 & 3.9 & A1 & 41 & 35 & 4.6 & 4.3 \\
\hline A & 63 & 49 & 5.8 & 5.2 & A2 & 61 & 50 & 6.8 & 7.2 \\
\hline A- & 107 & 94 & 9.8 & 9.9 & A3 & 76 & 64 & 8.5 & 7.9 \\
\hline BBB+ & 128 & 139 & 11.0 & 14.7 & Baa1 & 102 & 114 & 11.4 & 14.1 \\
\hline BBB & 171 & 173 & 15.6 & 18.3 & Baa2 & 129 & 159 & 14.5 & 19.6 \\
\hline BBB- & 113 & 103 & 10.3 & 10.9 & Baa3 & 101 & 100 & 11.3 & 12.3 \\
\hline BB+ & 99 & 68 & 9.0 & 7.2 & Ba1 & 99 & 53 & 11.1 & 6.5 \\
\hline BB & 98 & 70 & 9.0 & 7.4 & Ba2 & 68 & 64 & 7.6 & 7.9 \\
\hline BB- & 71 & 62 & 6.5 & 6.5 & Ba3 & 69 & 46 & 7.7 & 5.7 \\
\hline B+ & 70 & 29 & 6.4 & 3.1 & B1 & 53 & 36 & 5.9 & 4.4 \\
\hline B & 53 & 43 & 4.8 & 4.5 & B2 & 40 & 27 & 4.5 & 3.3 \\
\hline B- & 20 & 21 & 1.8 & 2.2 & B3 & 16 & 33 & 1.8 & 2.8 \\
\hline CCC+ & 10 & 11 & 0.9 & 1.2 & Caa1 & 12 & 11 & 1.3 & 1.4 \\
\hline CCC & 4 & 7 & 0.4 & 0.7 & Caa2 & 2 & 3 & 0.2 & 0.4 \\
\hline CCC- & 0 & 2 & 0.0 & 0.2 & Caa3 & 2 & 2 & 0.2 & 0.2 \\
\hline D & 1 & 6 & 0.1 & 0.6 & - & 0 & 4 & 1.0 & 0.5 \\
\hline & & & & & & & & \\
\hline
\end{tabular}

Central rating values are more frequent, as expected: there is only a small subset of all firms that achieve the higher levels; companies in worse conditions tend to disappear, and thus, are not rated. Again, this distribution is similar to those obtained in some additional samples, and to the whole population of companies in these databases. 


\section{Standard and Poor's versus Moody's ratings}

To evaluate the accuracy of both CRA's, Krämer and Güttler (2008) analyze the defaults predictions for a sample of companies bonds, and Ghosh (2013) studies the differences between Moody's and S\&P's long term credit ratings. But one has to consider the slight differences in both agencies definitions of ratings, that can explain, at least in part, the differences between the rates obtained; Moody's considers the "likelihood of a default on contractually promised payments and the expected financial loss suffered in the event of default" (Moody's Investors Service, 2016) while S\&P's considers "the obligor's capacity and willingness to meet its financial commitments as they come due, and may assess terms, such as collateral security and subordination, which could affect ultimate payment in the event of default", (Standard \& Poor's Ratings Services, 2014). Moody's refers to the expected loss, while S\&P's mentions the default probability, so this could justify the differences observed. On the other hand, Livingston et al. sample more than 1200 bond issues and do not find significant differences in the rating assigned by both agencies; while Bowe and Larik (2014) find that Moody's tends to be more conservative, in line with our results for firm's ratings. Bissoondoyal-Bheenick, (2004), founds also this split, and cites Mexico evaluation before its 1994 financial crisis, with a BB+ S\&P's rating against Moody's more conservative Ba. Moody's defaults were more concentrated on lower grades than S\&P's.

In our case, long term ratings are compared for the same firms and it can be seen that Moody's tends to assign lower grades than S\&P's. Pichereau (2016) analyzes the causes of differences in split ratings and concludes that $S \& P$ attributes more importance to the leverage ratio, while Moody's considers the total revenue as a prime factor.

Both valuation systems (S\&P and Moody's) are related, although the two companies have their methodology and sources of information, which are not totally public.

In the following table, both variables are crossed for our sample of 892 firms rated by both agencies. The frequencies in bold (main diagonal) correspond to the companies that have been valued in a coincident way by S\&P and by Moody's.

Considering that the twenty categories of each rating company are similar, it is observed that in 498 cases the valuation coincides in 2014; that is nearly $56 \%$, while in 2018 , 406 show the same rating, that is $52.19 \%$. This fact alone allows questioning the methodology followed since the previous classifications must measure a similar underlying magnitude: the probability of failure associated with each company, or a latent variable measuring credit risk. With data from the third big rating company, Fitch, the conclusion would come close to the same results. Nowadays Moody's tends to provide lower ratings; for 225 firms $(25.22 \%)$, in the first sample, while it happens to 209 companies $(26.86 \%)$ in 2018, its rates are one notch less than S\&P's, 41(4.60\%), in 2014, are two levels less, and five years later, there are 30 $(3.85 \%)$ and just 5 fall three or more levels less in both samples. On the opposite side, 114 companies (12.78\%) are rated one level higher by S\&P in 2014, and 112 (14.4\%) in 2018, and 7 two or more notches in the first sample, increasing to 15 , in the second. 
Table 3. Ratings of S\&P crossed with Moody's in 2014 and 2018

$$
\text { Moody's }
$$

2014 Aaa Аa Аa Аa А $\begin{array}{lllllllllllllllllll}1 & 2 & 3 & 1 & 2 & 3 & 1 & 2 & 3 & 1 & 2 & 3 & 1 & 2 & 3 & 1 & 2 & 3\end{array}$

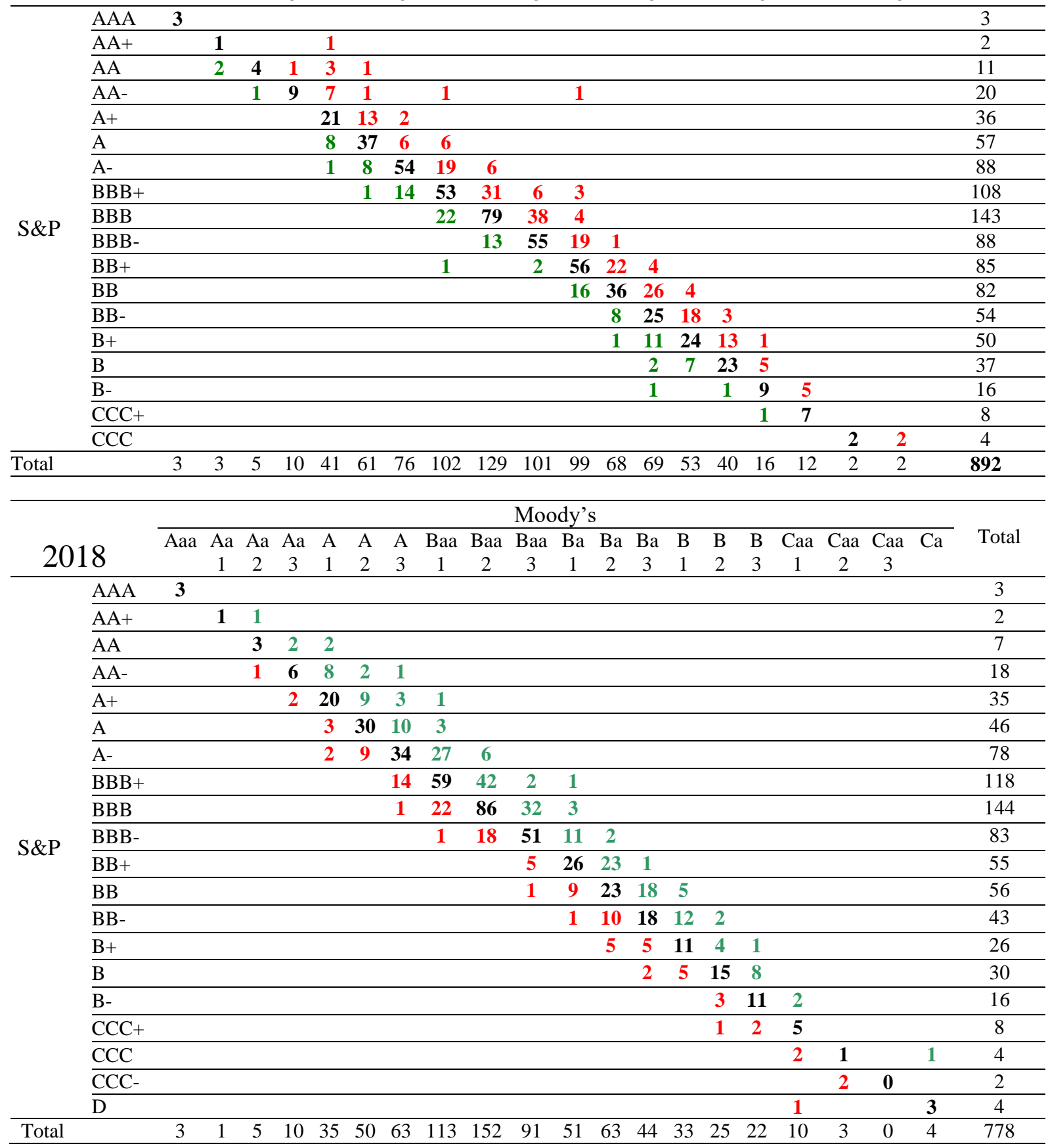

Although there is a high degree of coincidence in both CRA's, the differences have increased over time. These differences are evident in the prime categories, and even in the first levels of the non prime ratings, while the opposite occurs for lower ratings.

\section{Measuring and testing differences}

An inflation index is proposed, in order to measure the differences between the ratings attributed by both CRA's; it is based on the frequencies $n_{i j}$ in table 3 , to quantify the differences of one company $\mathrm{X}$ related to the other $\mathrm{Y}$ 


$$
R I I=\sum_{i=2}^{n} \sum_{j=1}^{i-1} \omega_{i-j} n_{i j} / \sum_{i=2}^{n} \sum_{j=1}^{i-1} n_{i j}-\sum_{i=1}^{n-1} \sum_{j=i}^{n-1} \omega_{j} n_{i j} / \sum_{i=1}^{n-1} \sum_{j=i}^{n-1} n_{i j}
$$

where the set of weights $\left\{\omega_{j}\right\}$ reflect the relative importance of the deviations between the rates assigned by each of the CRA's, being $\omega_{1}<\omega_{2}<\ldots<\omega_{n-1}$. When Moody's provides a higher rating than $\mathrm{S} \& \mathrm{P}$, the first term tends to increase RII, while the second term reflects the opposite situation. Thus negative values of RII are linked to a rating inflation of S\&P compared with Moody's ratings. The weights can be assigned in different ways; as there are practically no differences between ratings larger than two or three notches, defining the first weights is sufficient. One possibility is using the values $\omega_{j}=j$, for $j=1,2, \ldots, n-1$. The differences between the ratings assigned by S\&P and Moody's, in 2014, are RII $=-0.0294$, and -0.0258 in 2018; that is, there is a negative deviation indicating that Moody's ratings tend to be lower that S\&P. In this period, although there is an increase in the number of firms with different ratings in both CRA's, these differences tend to be lower, as detected with the RII index. It can be attributed either to a more homogenous evaluation of credit risk by both CRA's, or, to a reaction to try to smooth the biggest discrepancies between them. As the differential of higher ratings for S\&P's in comparison to Moody's has lowered at the same time that ratings have decreased globally, the correction is in the direction of lowering rating inflation.

It can be tested that the scores attributed by S\&P tend to be higher than those of Moody's. A Wilcoxon test (table 4) is performed to compare if one distribution is 'displaced' with respect to the other. This is confirmed as its $\mathrm{p}$-value is $p<0.001$. It could be concluded that Moody's ratings tend to show a score related to lower creditworthiness than those attributed by S\&P. Higher values are associated with greater probabilities of default, that is, with lower credit quality.

Table 4. Wilcoxon tests to compare S\&P and Moody's ratings

\begin{tabular}{llccc}
\hline 2014 & & $n$ & Average range & Sum of ranges \\
\hline Moody's - S\&P's & Negative ranges & 128 & 185,09 & 23768,00 \\
\cline { 2 - 5 } & Positive ranges & 275 & 209,59 & 57638,00 \\
\cline { 2 - 5 } & Ties & 502 & & $p=1.4 \times 10^{-15}$ \\
\hline 2018 & & $n$ & Average range & Sum of ranges \\
\hline Moody's - S\&P & Negative ranges & 127 & 182,93 & 23332,50 \\
\cline { 2 - 5 } & Positive ranges & 245 & 189,35 & 46145,50 \\
\cline { 2 - 5 } & Ties & 406 & & $p=1.694 \times 10^{-9}$ \\
\hline
\end{tabular}

In the following box diagram (figure 1), the larger values correspond to worse credit ratings (value 1 was associated with AAA or Aaa, and value 20 with D or Ca)

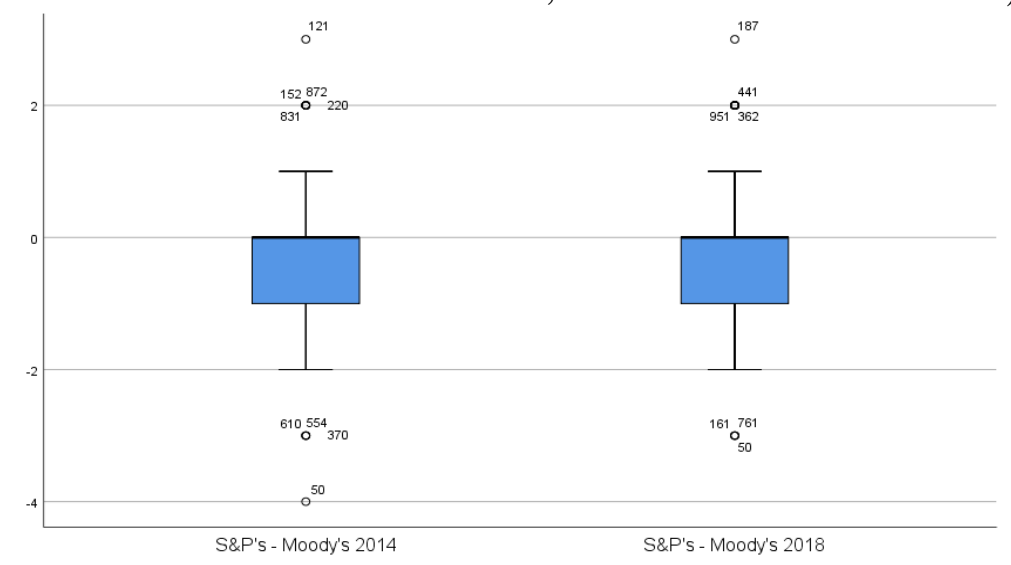

Figure 1. Differences in ratings by both CRA's, in 2014 and 2018 
For many companies, Moody's ratings tend to score slightly below S\&P's. Using numerical ordered values for the ratings, differences calculated for each company shows the tendency to award lower scores by Moody's. Figure 2 represents the differences between the frequencies of the numerical scores associated to the ordinal rates attributed by both CRA's to the same companies in the sample, confirming previous results.

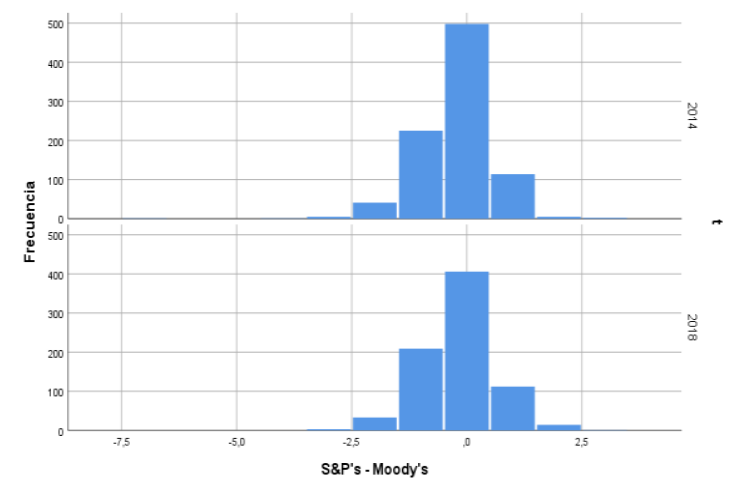

Figure 2. Distribution of differences between S\&P and Moody's ratings

Comparing the differences in rating between 2014 and 2018, the Wilcoxon test originates a p-value 0.298 , thus, these differences persist in this period.

In some sectors, ratings awarded by Moody's tend also to be lower than those of S\&P, as can be seen in the following table 5; Wilcoxon and sign tests are applied for several of the companies sectors included in both samples; p-values for the former, and the RII-indices are included for different sectors.

In the utilities, industrial, paper, healthcare and IT sectors, Moody's tends to be stricter than S\&P's when attributing ratings to companies, although their trend is to converge except in IT and utilities; in the consumer, hotels, medical, mining, chemical and energy sectors, there are no significant differences, although, S\&P seems to be somewhat stricter in the consumer sector. In almost half of both samples, ratings are equivalent for the two CRA's.

Table 5. Test's p-values and difference indices between S\&P and Moody's ratings

\begin{tabular}{lcccc}
\hline & \multicolumn{2}{c}{$\mathbf{2 0 1 4}$} & \multicolumn{2}{c}{$\mathbf{2 0 1 8}$} \\
\hline Consumer & $\boldsymbol{p}$ & $\boldsymbol{R I I}$ & $\boldsymbol{p}$ & $\boldsymbol{R} \boldsymbol{I}$ \\
\hline Energy & 0.496 & -0.0009 & 0.491 & -0.0064 \\
\hline Healthcare & 0.226 & 0.0207 & 0.331 & 0.0094 \\
\hline Hotels & $\mathbf{0 . 0 0 0}$ & -0.1350 & $\mathbf{0 . 0 0 0}$ & -0.1056 \\
\hline Industrials & 0.500 & -0.0050 & 0.500 & 0.0083 \\
\hline I.T. & $\mathbf{0 . 0 0 0}$ & -0.2514 & $\mathbf{0 . 0 0 0}$ & -0.0444 \\
\hline Media & $\mathbf{0 . 0 0 0}$ & -0.0165 & $\mathbf{0 . 0 0 5}$ & -0.0785 \\
\hline Mining & 0.500 & -0.0050 & 0.617 & 0.0026 \\
\hline Paper & 0.552 & -0.0167 & 0.304 & 0.0072 \\
\hline Quemical & 0.344 & -0.0057 & 0.383 & -0.0015 \\
\hline Retailing & 0.162 & -0.0097 & 0.307 & -0.0024 \\
\hline Telecom & $\mathbf{0 . 0 3 6}$ & -0.0539 & 0.166 & -0.0245 \\
\hline Utilities & $\mathbf{0 . 0 6 2}$ & -0.0070 & 0.443 & -0.0061 \\
\hline
\end{tabular}

Consequently, it seems clear that S\&P tends to obtain higher credit ratings than Moody's, all along the period considered. Notwithstanding, the structure of these differences changes with both agencies, being the net benefits, the cash flow and overall debt the main causes of these changes. It should be noted that it is the companies themselves that contract the rating agencies to calculate their ratings, and pay the fees for such work. Therefore, there 
is a possibility for a potential conflict of interest, resulting in rating inflation, showing a higher degree of solvency for a company, compared to a stricter judgment. Moody's tends to attribute slightly weaker ratings, and has fewer customers to rate.

Table 6. Financial ratios in different sector for groups 'favored' by each CRA

\begin{tabular}{|c|c|c|c|c|c|}
\hline Sector & & EBITDA margin & Net Benefit ratio & $\begin{array}{l}\text { Total Debt / } \\
\text { EBITDA }\end{array}$ & $\begin{array}{c}\text { Financial Debt / } \\
\text { Cash Flow }\end{array}$ \\
\hline \multirow[t]{2}{*}{ Consumer } & Moody's & 0.12 & 0.05 & 1.99 & 4.83 \\
\hline & $\mathrm{S} \& \mathrm{P}$ & 0.19 & 0.09 & 2.38 & 2.48 \\
\hline \multirow[t]{2}{*}{ Healthcare } & Moody's & 0.30 & 0.14 & 2.68 & 9.97 \\
\hline & S\&P & 0.24 & 0.13 & 2.31 & 4.33 \\
\hline \multirow[t]{2}{*}{ Industrial } & Moody's & 0.16 & 0.06 & 2.92 & 4.40 \\
\hline & S\&P & 0.12 & 0.06 & 2.04 & 8.73 \\
\hline \multirow[t]{2}{*}{ I.T. } & Moody's & 0.28 & 0.15 & 2.35 & 3.78 \\
\hline & $\mathrm{S} \& \mathrm{P}$ & 0.24 & 0.13 & 1.27 & 3.54 \\
\hline \multirow{2}{*}{ Mining } & Moody's & 0.36 & 0.09 & 1.89 & 3.30 \\
\hline & S\&P & 0.13 & 0.06 & 1.80 & 3.13 \\
\hline \multirow[t]{2}{*}{ Telecom } & Moody's & 0.44 & 0.02 & 3.80 & 6.34 \\
\hline & $\mathrm{S} \& \mathrm{P}$ & 0.40 & 0.04 & 3.75 & 5.50 \\
\hline \multirow[t]{2}{*}{ Utilities } & Moody's & 0.23 & 0.10 & 4.14 & 6.15 \\
\hline & S\&P & 0.33 & 0.12 & 4.15 & 7.35 \\
\hline \multirow[t]{2}{*}{ Total } & Moody's & 0.21 & 0.06 & 4.72 & 4.91 \\
\hline & S\&P & 0.22 & 0.09 & 2.73 & 4.64 \\
\hline
\end{tabular}

Several financial ratios obtained from the companies' public accounts are included in table 6. They are obtained from two groups of companies within the sample used; the first group is formed by companies with S\&P's rating better than Moody's (labeled 'S\&P', in the table), and the second group with firms favored by Moody's (labeled 'Moody's'). These data can highlight some differences in criteria in the evaluation process. In table 6 , the mean values of the ratios are presented for two sectors (Healthcare and Industrial) where rating inflation by S\&P (related to Moody's) is suspected, for two sectors (Telecom and Utilities) with much lower relative rating inflation, and for three sectors where ratings are with no observed bias.

S\&P's methodology seems to weight more the benefit data of firms, while Moody's tends to focus more on debt and cash flow. But both CRAs have different approaches in each sector, and this can explain in part the differences; but the detected trend in assigning higher ratings by S\&P in respect to Moody's should be associated with the influence of market considerations in the final assessments, as the financial ratios for different groups of firms do not show a clear trend in these ratios that could explain the differences.

\section{Conclusions}

Credit ratings are formulated as opinions about the situation of the creditworthiness of a company and its willingness, as an obligator, to meet its financial commitments. Nowadays the growing regulatory reliance on ratings, that are compulsory on many financial operations, produces curious effects: something that the own creators of the ratings present as mere opinions, is transformed in legal requirements for issuers or corporations and, in many cases, in compulsory conditions for investors, who, in fact, are outsourcing the evaluation of credit risk to justify their decisions. Until 1970, the investor-pays or subscription-based business model was the norm. Also, the demand for ratings remained stable; this system was by itself a guaranty of objectivity, but, was not sustainable; when photocopiers became ubiquitous, the information generated for a firm or bond issue was disseminated. Then, new CRA's came into 
the fray, and the need of rating expanded due to several circumstances, such as the expansion of funds institutionalizing investments, the disintermediation at the margin of the financial firms, and the globalization process, in the present century. Fees are usually paid by the issuers or by the firms rated, and issuers were eager to show to potential investors their soundness. This state of affairs tends to lower the issuer's firms financial costs, producing and endogenous effect on the markets. Possible conflict of interest became apparent, just contained by the willingness of CRA's in preserving their reputation; but this counterweight cannot produce the same desirable effect on all the CRA's customers, and the reputational concerns could differ depending on the rated firm's size, its market clout and the relative situation of oligopoly by some CRAs in particular sectors. The appearance of Fitch, that is, the increase of competition in the CRA's environment, produced contradictory effects: rating inflation was clear, as one would expect, as in the issuer-pay's model, a firm has a clear interest in obtaining higher grades, considering that this would lead to lower spread in its financing. With more CRA's to shop around, the prospect of a higher rating is a plus, when deciding the agency to contract. As stated by L. Stout cited by Rapoport (2010), 'When the people being watched get to choose their watchdog, they aren't going to select the toughest animal around'. The quality of ratings is something that can only be evaluated in the future (today, with past statistical information about failures, the results can only be applied to what has already happened), and, as these are 'opinions', what responsibility could be associated to the exercise of free speech? Although, Moody's pretends to associate a forecasting power to their ratings, but, again, the only real 'guaranty' of this declaration is the reputational concern of failure of a company or of a security; in case of firms with fundamental soundness in its situation, this counterweight could be of no practical value. Also, a pressure of the CRAs upon the issuers is possible, producing an opposite effect. But, as long as there are not clear and measurable incentives or effects upon the quality of ratings, it will not be possible to diminish this bias in the rates produced.

The possible strict regulation of CRA's is polemic. The creation of public agencies is not very reassuring, as they would not risk even their reputation, in case of errors, and the civil servants appointed to these potential public agencies, would they respond to clear mistakes in theirs judgments? Nothing traumatic has originated by the implementation of Basel II guidelines. The return to a pre-1970 issuer-pays model is not economically viable for the CRA's, although the subscriber-pays model, which is followed by some smaller agencies, comes closer to the issuer-pays situation that ended half a century ago. A necessity of a clearer picture of how ratings are calculated, is necessary to add transparency to the market; also it is obvious the need of publicity about the statistical past performance of the CRAs, with firms and issues public data attached; this should increase the reputational costs inherent to the rating process. Abandon explicit regulatory reliance on ratings would diminish possible conflicts of interest, but would institutional investors by-pass CRA's? Not having a clear way to proceed in order to increase the quality of ratings, at least the information about the agencies results could be presented in a unified way, to promote studies about rating the raters, and these comparative studies could be made public by regulators, to create a clear incentive for maintaining a high reliability of rates.

When analyzing differences of ratings obtained by S\&P's and Moody's, the first conclusion is that in more than half of the companies, the evaluation of both CRA's are coincident. But, in many cases systematic deviations are noteworthy, and provide clues of how the agencies react to these differences, lowering them in many cases. Also the predominance of some CRAs in particular economic sectors can distort the rating results. The contributions to the market include not only evaluating the creditworthiness of firms, but also to define a common way of referring to credit risk of issues and firms, and, thus, to enable 
objective comparisons among them. These assessment functions have been provided, in the past, by different actors such as the financial press, credit reporting agencies, and bankers underwriting issues of securities. This environment is reported with a unique figure: the rating assigned to a company or to a financial product. In mathematical Statistics, the absence of loss of information due to the reduction of dimension when processing a sample, is called 'sufficiency', but there seems not to be very academic interest in evaluating the 'sufficiency' of the rates attributed by CRA's. An exception can be found in the cited Minescu (2010) paper. In fact, it is not surprising that, from time to time, 'outliers' such as the events associated to Enron, Parmalat, Lehman,..., arouse, leading to substantial loses borne by investors, employees, customers of firms, and pension funds holders; and this leads to questioning the agencies precision and ways of summarizing the financial and economic information.

The market of agencies is based on the three larger agencies, with important entry barriers. They compete between them for a limited number of issues and organizations, but not in improving the quality of ratings. In theory, when the markets conditions deteriorate, ratings for all of them should get lower. Nowadays, Moody's ratings tend to be lower than S\&P's, in ordinary times, in several sectors, while they are almost coincident for consumers and energy firms. In any case, a fact is that ratings are not predictive measures; they are based on past information; in most cases, incomplete. But, they are managed and manipulated as they were predictive measures of the future health of companies and financial issues. This is not the case.

\section{References}

Altman E.I. and Rijken H.A. (2004). How Rating Agencies Achieve Rating Stability, Journal of Banking and Finance, 28, 11, 2679-2714. Retrieved, November 20, 2019. https://doi.org/10.1016/j.jbankfin.2004.06.006

Australian Securities \& Investments Commission (2018). Surveillance of Credit Rating Agencies. $\quad$ Report $566 . \quad$ https://asic.gov.au/regulatory-resources/find-adocument/reports/rep-566-surveillance-of-credit-rating-agencies/

Bae, Kee-Hong, Jun-Kii Kang and Jin Wang (2015). Does increased competition affect credit ratings? A reexamination of the effect of Fitch's market share on credit ratings in the Corporate Bond Market. Journal of Financial and Quantitative Analysis, 50, 5, 1011 1035. https://doi.org/10.1017/S0022109015000472

Beatty, A., Gilette, J., Petacchi, R. and Weber, J. (2019). Do rating agencies benefit from providing higher ratings? Evidence from the consequences of municipal bond ratings recalibration. Journal of Accounting Research, 57, 2, 323-354. https://doi.org/10.1111/1475-679X.12263

Becker, B. and Milbourn, T. (2009). Reputation and competition: evidence from the credit rating industry, Harvard Business School, Working Paper No. 09-051.

Becker, B. and Milbourn, T. (2011). How Did Increased Competition Affect Credit Ratings? Journal of Financial Economics, 101, 493-514. https://doi.org/10.1016/j.jfineco.2011.03.012

Belas, J.; Bilan, Y.; Kijucnicov, A. and Vincurova, Z. (2015). Actual problems of business risk in SME segment. Case study from Slovakia. International Journal of Entrepreneurial Knowledge, 3, 1, 46-56. https://doi.org/10.1515/ijek-2015-0010

Bissoondoyal-Bheenick, E. (2004). Rating Timing Differences between the two leading Agencies: Standard and Poor's and Moody's. Emerging Markets Review, 5, 3, 361-378. https://doi.org/10.1016/j.ememar.2004.03.006 
Blaurock, U. (2007). Control and Responsibility of Credit Rating Agencies. Electronic Journal of Comparative Law, 11, 3, Dec. http://www.ejcl.org/113/article113-16.pdf.

Bonsall, S. (2014). The Impact of Issuer-Pay on Corporate Bond Rating Properties: Evidence from Moody's and S\&P Initial Adoptions. Journal of Accounting and Economics, 57, 89-109. https://doi.org/10.1016/j.jacceco.2014.01.001

Bonsall, S., J. Green and K. Muller (2018). Are Credit Ratings more rigorous for widely covered firms?. The Accounting Review, 93, 6, 61-94. https://doi.org/10.2308/accr$\underline{52044}$

Bowe, M. and Larik, W. (2014). Split Ratings and Differences in Corporate Credit Rating Policy between Moody's and Standard \& Poor's. Financial Review, 49, 4, 713-734. https://doi.org/10.1111/fire.12054

Chodnicka-Jaworska, P. (2017). Banks' credit ratings inflation. Olsztyn Economic Journal, 1, 99-114.

Engelmann, B., Hayden, E. and Tasche, D. (2003). Testing rating accuracy. Risk, 16, 82-86. https://www.risk.net/risk-management/1528680/testing-rating-accuracy

Escrig-Olmedo, E., Fernández-Izquierdo, M.A., Ferrero-Ferrero, I., Rivera-Lirio, J.M. and Muñoz-Torres, M.J. (2019). Rating the Raters: Evaluating how ESG Rating Agencies Integrate Sustainability Principles. Sustainability, 11, 3, 915. https://doi.org/10.3390/su11030915

Frenkel, S. (2015). Repeated Interaction and Rating Inflation: A Model of Double Reputation. American Economic Journal: Microeconomics, 7(1), 250-280.

https://www.jstor.org/stable/24467042

Ghosh, S. (2013). A Study of Differences in Standard \& Poor's and Moody's Corporate Credit Ratings, 1-14. http://www.stern.nyu.edu/sites/default/files/assets/documents/con_041250.pdf

Goldstein, I. and C. Huang (2020). Credit rating inflation and firms' investments. The Journal of Finance, July, https://doi.org/10.1111/jofi.12961

Hemraj, M. (2015). Credit Rating Agencies. Springer International Publishing. https://doi.org/10.1007/978-3-319-17927-8

Josephson, J. and J. Shapiro (2020). Credit Ratings and Structured Finance. Journal of Financial Intermediation, 41, 100816, 1-15, https://doi.org/10.1016/j.jfi.2019.03.003

Krämer, W. and A. Güttler (2008). On comparing the accuracy of default predictions in the rating industry. Empirical Economics, 34(2), 343-356. https://doi.org/10.1007/s00181-007-0125-6

Kartasheva, A.V. and Yilmaz, B. (2020) Precision of Ratings. Jacobs Levy Equity Management Center for Quantitative Financial Research Paper.

https://ssrn.com/abstract=2232998 or http://dx.doi.org/10.2139/ssrn.2232998

Livingston, M., Wei, J. and Zhou, L. (2010). Moody's and S\&P Ratings: Are They Equivalent? Conservative Ratings and Split Rated Bond Yields. Journal of Money, Credit and Banking, 42, 7, 1267-1293. https://doi.org/10.1111/j.15384616.2010.00341.x

Mathis, J., McAndrews, J. and Rochet, J. (2009). Rating the Raters: Are Reputation Concerns Powerful Enough to Discipline Rating Agencies? Journal of Monetary Economics, 56, 657-674. https://doi.org/10.1016/j.jmoneco.2009.04.004

Minescu, A.M. (2010). Rating Agencies - General Issues and Potential Solutions. PetroleumGas University of Ploiesti Bulletin, Economic Sciences Series LXII 2, 110-115.

Pichereau, L. (2016). Empirical study of credit rating agencies: do the financial characteristics of companies have an impact on the occurrence of split ratings? Thesis. 
Rapoport, M. (2010) Role of auditors in crisis gets look. Wall Street Journal, December, 23

Sabatino, M. (2014). The Business Model of Rating Agencies between Asymmetric Information and Financial Crises. Journal of Economics and Development Studies, Dec., 2, 4, 165-183. https://doi.org/10.15640/jeds.v2n4a12

Skreta, V. and L. Veldkamp (2009). Ratings Shopping and Asset Complexity: A Theory of Ratings Inflation. Journal of Monetary Economics 56(5), 678-695.

Whalen, P. S. (2016). The Issuer-Pays Model: "Big Four" Auditors and Credit Rating Agencies Share a Common Conflict. University of Tennessee Honours Thesis Projects. https://trace.tennessee.edu/utk_chanhonoproj/1963

White, L. J. (2018). The Credit Rating Agencies and their role in the Financial System. In E. Rousseau, ed., Oxford Handbook on Institutions, International Economic Governance, and Market Regulation, Oxford University Press. https://papers.ssrn.com/sol3/papers.cfm?abstract_id=3192475

Xia, H. and G. Strobl (2012). The Issuer-Pays Rating Model and Ratings Inflation: evidence from Corporate Credit Ratings. SSRN Electronic Journal, February, 1-44. https://doi.org/10.2139/ssrn.2002186

Yakymova, L. and Kuz, V. (2019). The use of discriminant analysis in the assessment of municipal company's financial health. Economics \& Sociology, 12, 2, 64-78. https://doi.org/10.14354/2071-789X.2019/12-2/4 